\title{
Inquiry on the Transmission of U.S. Aggregate Shocks to Mexico: A SVAR Approach*
}

\author{
Julio A. Carrillo $\quad$ Rocio Elizondo ${ }^{\ddagger} \quad$ Luis G. Hernández-Román ${ }^{\S}$ \\ Banco de México \\ Banco de México \\ Banco de México \\ Preliminary Draft \\ This Version: February 2017
}

\begin{abstract}
We study the transmission of U.S. macro shocks to the Mexican economy. We use a SVAR model to identify, using sign and zero restrictions, six aggregate disturbances originated in the U.S., such as changes in economic policy uncertainty, total factor productivity (TFP), aggregate demand, cost-push shocks, and two types of monetary policy shocks. We then document how these foreign shocks propagated to Mexico over the period 2002Q1-2016Q2. We find that U.S. aggregate shocks may explain up to 78\% of output fluctuations in Mexico in the long run, and around $60 \%$ of core inflation volatility. Further, our results suggest that shocks to U.S. aggregate demand are the more important foreign disturbances affecting Mexican output. In contrast, uncertainty shocks to U.S. economic policy explain little of Mexican output volatility, even if economic activity seemed to respond to this shock in both countries. Our evidence suggests that the economic policy uncertainty shock was mainly absorbed by the nominal exchange rate, explaining around $20 \%$ of its fluctuations.
\end{abstract}

Keywords: Zero Restrictions, Sign Restrictions, Small Open Economy, Monetary Policy Normalization.

JEL Classification: C32, E52.

\footnotetext{
${ }^{*}$ Any views expressed herein are those of the authors and do not necessarily reflect those of Banco de México.

${ }^{\dagger}$ Banco de México, Directorate of Economic Studies, DGIE, Calle 5 de Mayo \#18, C.P. 06069, Mexico City, Mexico. Tel. +52-55-5237-2701. Email: jcarrillo@banxico.org.mx

${ }^{\ddagger}$ Banco de México, Directorate of Economic Studies, DGIE, Calle 5 de Mayo \#18, C.P. 06069, Mexico City, Mexico. Tel. +52-55-5237-2453. Email: melizondo@banxico.org.mx

${ }^{\S}$ Banco de México, Directorate of Economic Studies, DGIE, Calle 5 de Mayo \#18, C.P. 06069, Mexico City, Mexico. Tel. +52-55-5237-3558. Email: 1hernadez@ banxico.org.mx
} 


\section{Introduction}

Economists and policymakers have always been concerned on how economies interact across borders. The reason for this interest is quite simple: we could cast better policies to reduce inefficient fluctuations in domestic output if we better understand the transmission mechanisms of changes in foreign economic conditions across borders, and measure the extent to which these changes affect economic activity, inflation, and asset prices at home. This seminal topic in international economics has suddenly recovered a significant importance in the current state of the world, as drastic changes in economic policy are expected in Europe and North America. It is of course too soon to gauge the full consequences, in terms of geopolitics, trade policies, capital flows, and migration, of Brexit and the triumph of Donald J. Trump as the 45th President of the U.S. So far, we have witnessed an important amount of uncertainty surrounding future economic policies, but what it is certain is that the economic platform in both regions will evolve. In this context, the question of how changes in foreign conditions affect the domestic economy seems more relevant than ever for policymakers in order to prepare for what is yet to come. In this paper, we aim to shed light on this question by analyzing the relationship between Mexico and the U.S., a relationship that it is expected to change in the future.

In particular, we investigate how U.S. aggregate shocks have affected the dynamics of Mexican macro variables in a recent period, from 2002Q1 to 2016Q2. Mexico is a prototype emerging market economy and its relationship with the U.S. economy, in terms of trade, migration, and capital flows, is enormous. ${ }^{1}$ The present case study for the Mexican economy can thus serve other researchers and policymakers interested in analyzing the international propagation of shocks and business-cycle synchronization between large and small open economies (including emerging market economies or EMEs, for short), and it complements a vast literature on the international propagation of shocks between countries.

We center our investigation on aggregate macro variables, such as output, inflation, interest rates, and the exchange rate, and leave out important dimensions such as migration or capital flows. In particular, we use a joint SVAR model for Mexico and the U.S., esti-

\footnotetext{
${ }^{1}$ For instance, about $80 \%$ of Mexican exports are bought in the U.S., while 50\% of Mexican imports are made in the U.S. Also, in the period studied the degree of openness (i.e., the exports-plus-imports-to-GDP ratio) of the Mexican economy increased from around 50\% to almost 70\%, while 50\% of foreign direct investment in Mexico comes from the U.S. Finally, the volume of remittances sent by Mexican migrants increased from 3\% of the total income received in the current account in 2000 to $6 \%$ by the end of the sample, with a peak of $9 \%$ before the financial crisis.
} 
mated through Bayesian techniques, and assume that the U.S. aggregate dynamics are blockexogenous to those of Mexico. ${ }^{2}$ With six U.S. variables in the SVAR, ${ }^{3}$ we use a combination of sign and zero restrictions to identify six structural shocks originating in the U.S. These shocks measure the effects on the U.S. economy of unexpected changes to aggregate demand, total factor productivity (or TFP), the uncertainty surrounding economic policies, cost-push innovations, and two types of monetary policy shocks. Since we want to remain agnostic about the responses of Mexican variables to these shocks, we do not impose any restrictions on them and let the data speak for themselves. Further, as our SVAR identifies as many shocks as U.S. variables, we are able to run a variance decomposition to measure the proportion of Mexican business-cycle fluctuations explained by foreign and domestic shocks, and a historical decomposition of observed variables into shocks. The latter allows to run counterfactual exercises with alternative scenarios, such as what would have happened to U.S. and Mexican variables if monetary policy in the U.S. had not been constrained by the zero lower bound (ZLB) during the financial crisis.

While the shocks to aggregate demand, TFP, and the cost-push disturbances are relatively standard in the literature, ${ }^{4}$ the other three shocks we identify deserve some explanation. Regarding the monetary policy shocks, we identify a regular type and a bumpy type. Both shocks have in common that after an unexpected increase in the policy interest rate, output and inflation fall over time, which is the usual finding regarding these shocks in the literature. The difference between them lies in their effects on the Ten-year Treasury term premium, which is defined as the compensation that Ten-year bond investors ask for bearing the risk that short-term interest rates evolve differently than expected during the life of the bond. If investors judge that the economy will do fine in the future, the term premium tends to decrease, while if they think that the road ahead is bumpy, the term premium tends to rise. ${ }^{5}$ We assume that under a regular monetary policy shock, the Treasury term premium falls after an increase in the short-term policy rate. Our interpretation is that investors see this change in monetary

\footnotetext{
${ }^{2}$ That is, we assume that neither Mexican variables nor shocks affect the behavior of U.S. variables. Hernández and Leblebicioglu (2015) formally test this hypothesis and do not find evidence to reject it.

${ }^{3}$ These variables are the CBO output gap, core PCE inflation, the Wu and Xia (2016)'s shadow Fed funds rate, the Baker, Bloom and Davis (2015)'s EPU index, the Basu, Fernald, and Kimball (2006)'s adjusted utilization-adjusted TFP growth series, and Adrian, Crump and Moench (2013)'s measure of the 10-year Treasury term premium.

${ }^{4}$ The aggregate demand shock is identified as one that moves output, inflation, and the short-run nominal interest rate in the same direction. A cost-push shock is one that moves output and inflation in opposite directions. Finally, for the TFP shock, we assume that it is exogenous to the rest of macro variables.

${ }^{5}$ For further details, see this entry of the NY Fed's Liberty Street Economics Blog.
} 
policy as an adequate response conducive to economic stability, like for instance a policy that aims to keep inflation under control. In contrast, we assume that under a bumpy monetary policy shock, the Treasury term premium increases after an increase in the policy rate. As such, we interpret that investors judge that this change in monetary policy may destabilize the economy. For instance, the IMF's 2013 Spillover Report warned than an accelerated normalization of U.S. monetary policy, in which the long-term rates increase as a consequence of a bumpy exit strategy, could entail a slower U.S. recovery and even a recession. ${ }^{6}$ In this context, one may expect that a bumpy monetary policy shock would have a stronger impact on the Mexican economy than a regular one. In this paper, we investigate whether this is the case.

Regarding the last shock, Baker et al. (2015) developed an index of economic policy uncertainty in the U.S. (EPU for short), that aims to measure the number of times U.S. newspapers talk about uncertainty surrounding economic policy. ${ }^{7}$ As one might expect, in the recent period this index spiked around the default of Lehman Brothers, major fiscal disputes in the U.S. Congress (like the 2011 debt-ceiling episode), and in the aftermath of Trump's election. Baker et al. (2015) show that U.S. output and investment fall persistently after an increase in the EPU index. It is thus natural to ask how much of these disturbances were transmitted to Mexican output and how much were absorbed by the peso/dollar exchange rate.

We find three main results. First, the evidence suggests that the six U.S. macro shocks identified may explain near to $80 \%$ of the Mexican output volatility in the long run, while the rest would be explained by domestic shocks. Also, the shock to U.S. aggregate demand explains around $25 \%$ of Mexican output fluctuations, and seem to lead the business-cycle synchronization between the two countries, as output moves in the same direction in both countries after these shocks. In contrast, U.S. TFP shocks may explain less than a tenth of Mexican output volatility, while they move output in opposite directions in each country. Finally, the other two shocks play a relative minor role in explaining Mexican output fluctuations (more on this below). With respect to Mexican core inflation, the results point that U.S. shocks can only explain around $65 \%$ of its volatility, and so inflation appears to be more domestically driven than output.

\footnotetext{
${ }^{6}$ See the "exit without growth" scenario in the aforementioned IMF's report.

${ }^{7}$ This index is now available at the St. Louis Fed's FRED database.
} 
Second, we find that a bumpy monetary policy shock has on average a deeper effect on Mexican output and inflation than a regular monetary policy shock. After a contractionary monetary policy shock, economic activity slowdowns in both countries, and the Mexican peso depreciates. If the monetary shock is a regular one, then a rise in the U.S. policy rate is not followed by a rise in the Mexican policy rate. Also, in this case inflation does not exhibit a significant change despite the depreciation. However, if the monetary shock is a bumpy one, Mexican output deteriorates more and inflation shows an upward pressure four quarters after the shock. In this case, we do not find evidence that the Mexican policy rate follows the U.S. policy rate. Interestingly, we find that Mexico's country risk, as measured by the EMBI rate, increases on impact after a bumpy monetary shock while it decreases for two quarters after a regular one. This finding is in line with the perception that after a bumpy shock, the risk premia asked by investors increases as their perceptions on the economy deteriorates, in this case in both countries.

Third, after an economic policy uncertainty (EPU) shock, U.S. output, inflation, and the policy rate fall, while in Mexico output falls moderately, the exchange rate depreciates, inflation increases, and the policy rate initially increases and then falls below equilibrium. Interestingly, while the EPU shock explains around $20 \%$ of output fluctuations in the U.S., it only explains around 5\% of output volatility in Mexico. However, this shock explains $20 \%$ of the exchange rate volatility, and it is by far the more important U.S. shock in terms of its explaining power for this variable. Our interpretation of this result is that, although the EPU shock seems to be an important driver of the U.S. economy for the period studied, it is mainly absorbed in Mexico by the exchange rate, which leads to upward pressures on inflation and the monetary policy rate. As anecdotal evidence of this effect, since Trump's victory in the U.S. election of November 8th and until his swearing-in ceremony in January 20th 2017, the Mexican peso depreciated 20\% against the dollar, while the U.S. EPU index practically doubled on a weekly-average basis with respect to the average level it observed during all 2016 before the election.

Finally, we perform a historical decomposition of U.S. and Mexican variables into shocks in order to assess whether the estimated SVAR tells a plausible economic story about the estimated period. ${ }^{8}$ For the U.S., we find that the SVAR interprets that the 2008 financial crisis was largely driven by the aggregate demand shock, and to a lesser extent to contractionary

\footnotetext{
${ }^{8}$ To perform this exercise, we select the sign-identified model whose impulse responses were the closest to the median responses of all sign-identified models. For more on this, see Fry and Pagan (2011).
} 
monetary policy shocks. Here, it is important to mention that we use the Wu and Xia (2016)'s shadow policy rate as a measure of U.S. monetary policy. This rate aims to map unconventional monetary policy (or UMP) measures into the policy rate, assuming that the latter could take negative values. However, as it is well known, UMP measures are at best imperfect substitutes of the fed funds rate. In this context, the finding that the financial crisis was deepened by contractionary monetary policy shocks can be thus interpreted as a consequence of the ZLB and the implementation of an imperfectly substitute monetary policy during the financial crisis. Inspired in this conjecture, in a counterfactual exercise, we ask the model what would have happened if the contractionary monetary policy shocks had never existed after the default of Lehman. The results of this exercise suggest that the recession in the aftermath of the crisis in both U.S. and Mexico would have not been as deep as it was, but the duration would have remained the same. Of course, this exercise is subject to the Lucas critique, since it assumes agent's expectations do not change, which is an unrealistic assumption. However, the exercise is informative about the transmission mechanism of U.S. monetary policy to Mexico.

\subsection{Selected literature review}

The literature studying the propagation of shocks across borders is vast and growing at a great speed. Some recent examples include Canova (2005), who finds that countries with a floating exchange rate regime are less exposed to the transmission of U.S. monetary policy shocks than countries with currency boards or similar arrangements. More recently, García-Verdú and Ramos-Francia (2014), Takáts and Vela (2014), and Mohanty (2014) document that the monetary policy of advanced economies is transmitted to EMEs mainly through changes in the policy rate, long-term interest rates, the exchange rate, and portfolio flows. They also find that the policy rate is the most important factor in economies with a fixed exchange rate regime. In contrast, the effects of the foreign monetary policy are mainly absorbed by the exchange rate in floating regimes. In addition, a number of central banks suggest that the monetary policy of advanced economies can affect commodity prices, international credit conditions, and inflation expectations (see Mohanty, 2014).

The aftermath of the financial crisis has also encourage economists to consider other sources of economic fluctuations such as financial and uncertainty shocks. In particular, the latter has been shown to be an important driver of the U.S. business cycle. Bloom (2009) and, more recently, Caldara, Fuentes-Albero, Gilchrist and Zakrajek (2016) document that 
industrial production in the U.S. responds quickly to an increase in economic uncertainty and find a decline in economic activity ranging from 0.5 percent to 1 percent after a one standard deviation in economic policy uncertainty. In comparison to the U.S. and other advanced economies, Carrire-Swallow and Céspedes (2013) find that EMEs suffer much more severe falls in investment and private consumption following an exogenous uncertainty shock, take significantly longer to recover, and do not experience a subsequent overshoot in activity.

Literature concerning the transmission of advance economies shocks to EMEs have focus on the effects of foreign monetary policy. In particular, Canova (2005) studies the transmission of U.S. monetary, demand, and supply shocks to Latin American economies. He uses a SVAR with block-exogeneity assumption and a sign restrictions identification, and finds that while demand and supply shocks do not play an important role, monetary shocks produce significant fluctuations in Latin America. The financial channel plays an important role in the transmission. Countries with floating exchange rate regimes are less exposed to the transmission of U.S. shocks than non-floaters, and display similar output but different inflation and interest rate responses.

Takáts and Vela (2014) study how monetary policy in advanced economies affects financial condictions in EMEs. Based on a VAR analysis the authors find evidence for the working of several international transmission channels. In particular, they find that EME policy rates reacted less to advanced economy monetary policy after the 2008 crisis, while their long-term interest rates have reacted more to changes in long-term rates in advanced economies. Their analysis also suggests that changes in the U.S. long-term interest rates are associated with significant effects on portfolio flows to EMEs and international reserves.

Chen, Griffoli and Sahay (2014) analyze the effects of U.S. monetary policy shocks on capital flows and asset prices movements in EMEs from 2000 to 2014. By developing a new methodology to extract, separate, and interpret U.S. monetary policy shocks, they find that the U.S. monetary policy had significant effects on capital inflows and asset price movements in EMEs during the implementation of unconventional monetary policy. However, these effects were minor in countries with stronger fundamentals. They argue that larger spillovers stem more from structural factors, such as the use of new instruments (asset purchases).

The rest of the paper is organized as follows. The next section describes the estimation methodology of the reduced-form VAR model, along with our shock-identification approach. Section 3 presents the data we use, and Section 4 discusses the main results, including IRFs, variance decomposition and the historical decomposition. In addition, we discusses two 
counterfactual exercises to study importance of the propagation of U.S. aggregate demand and monetary policy shocks to Mexico. Finally, section 5 concludes.

\section{The Structural VAR}

We now describe the VAR model and the set of assumptions that we make to identify six different U.S. aggregate disturbances, namely, an uncertainty shock, a productivity shock, an aggregate demand shock, a cost-push shock, and two types of monetary policy shocks. We use a combination of sign and zero restrictions to identify such structural innovations. The VAR model is estimated by using Bayesian techniques. Since we are interested in characterizing the propagation of these shocks in Mexico, we resort to a VAR with block-exogeneity, which we describe next.

\subsection{A VAR model for a small open economy}

Let $Y_{t}$ be a vector of $n$ domestic variables and $Z_{t}$ a vector of $m$ foreign variables at time $t$. We assume that $Z_{t}$ is block exogenous to the domestic variables. This means that the elements of $Y_{t}$ do not affect any of the values in $Z_{t+k}$ for any $k \geq 0$. We assume indeed that the domestic economy is too small in comparison with the large foreign economy, so the former cannot affect the dynamics of the latter - the small open economy assumption. The joint aggregate dynamics are thus represented by

$$
\begin{aligned}
& Z_{t}=f+\sum_{\ell=1}^{p} A_{\ell} Z_{t-\ell}+\eta_{t} \\
& Y_{t}=c+\sum_{\ell=1}^{p} B_{\ell} Z_{t-\ell}+\sum_{\ell=1}^{p} C_{\ell} Y_{t-\ell}+\varepsilon_{t},
\end{aligned}
$$

where $c$ and $f$ are vectors of constants, $A_{\ell}, B_{\ell}$ and $C_{\ell}$ are matrices of parameters, and $\xi_{t}=$ $\left[\eta_{t} \varepsilon_{t}\right]^{\prime}$ is a vector of reduced-form innovations with mean zero $\left(\mathrm{E}\left(\xi_{t}\right)=0_{(n+m) \times 1}\right)$, not autocorrelated $\left(\mathrm{E}\left\{\xi_{t} \xi_{t-\ell}^{\prime}\right\}=\mathbf{0}_{(n+m)}\right.$ for $\left.\ell \neq 0\right)$, and with a variance-covariance matrix equal to $\mathrm{E}\left\{\xi_{t} \xi_{t}^{\prime}\right\}=\Omega$.

\subsection{Structural VAR}

Let the $(n+m) \times 1$ vector $v_{t}$ denote a set of fundamental innovations representing shocks to the U.S. and the Mexican economy, with $\mathrm{E}\left\{v_{t} v_{t}^{\prime}\right\}=\mathbf{I}_{(n+m)}$ the identity matrix. Our 
shock-identification strategy consists in finding a set of models $\left\{\mathcal{A}_{k}\right\}_{k}$ so that, for each $k$, $\xi_{t}=\mathcal{A}_{k} v_{t}$, and $\Omega=\mathcal{A}_{k} \mathcal{A}_{k}^{\prime}$. ${ }^{9}$ As it is well known, many matrices $\mathcal{A}_{k}$ solve the above system, and so to identify economically meaningful structural shocks, we impose constraints on the elements of matrices $\mathcal{A}_{k}$ by using a combination of sign and zero restrictions. To satisfy block-exogeneity, and the small open economy assumption, we assume that none of the structural Mexican shocks have an effect on the dynamics of the U.S. variables. The latter implies that a block of matrix $\mathcal{A}_{k}$ will contain zeros. For simplicity, we assume that all structural U.S. shocks are ordered before the Mexican ones in vector $v_{t}$. Thus, the candidate SVAR models, $\mathcal{A}_{k}$, have the following structure:

$$
\mathcal{A}_{k} \equiv\left[\begin{array}{cc}
\mathcal{A}_{Z Z} & \mathbf{0} \\
\mathcal{A}_{Z Y} & \mathcal{A}_{Y Y}
\end{array}\right]
$$

where $\mathcal{A}_{Z Z}$ denotes the impact effect of U.S. shocks on U.S. variables, $\mathcal{A}_{Z Y}$ denotes the said effect on Mexican variables, and $\mathcal{A}_{Y Y}$ represents the impact effect of Mexican shocks on Mexican variables. We identify six different U.S. aggregate disturbances related with fundamentals: (i) an uncertainty shock, (ii) a productivity shock, (iii) an aggregate demand shock, (iv) a cost-push shock, (v) a regular monetary policy shock, and (vi) a bumpy monetary policy shock. We make the respective identification on six key U.S. variables, such as the change in the Economic Policy Uncertainty (EPU) index (epu $\left.u_{t}^{u s}\right)$, the change in productivity $\left(t f p_{t}^{u s}\right)$, the output gap $\left(y_{t}^{u s}\right)$, the core inflation $\left(\pi_{t}^{u s}\right)$, the short-term interest rate $\left(i_{t}^{u s}\right)$, and the Treasury term premium $\left(t t p_{t}^{u s}\right)$. Here, the EPU index and productivity are exogenous to the remaining U.S. variables. More details about these variables are given in the next Sections. The sign restrictions we use for our identification are summarized in Table 1.

The restrictions apply only to the partition $\mathcal{A}_{Z Z}$ of the SVAR model $\mathcal{A}_{k}$. We impose no restrictions on the partition $\mathcal{A}_{Z Y}$, as we aim to remain as agnostic as possible about the effect of U.S. shocks on Mexican variables. The signs are motivated by a vast class of DSGE models with nominal rigidities, such as Smets and Wouters (2007). For an uncertainty shock and a positive productivity shock, the EPU index and productivity increase, respectively, and we put no signs on the responses of the other variables. For a positive aggregate demand shock, we assume that the output gap, the core inflation, and the short-term interest rate increase,

\footnotetext{
${ }^{9}$ The relationship between the reduced-form VAR and the SVAR is evident if we pre-multiply system (1) and (2) by the matrix $\mathcal{A}_{k}^{-1}$, i.e.,

$$
\mathcal{A}_{k}^{-1}\left[\begin{array}{c}
Z_{t} \\
Y_{t}
\end{array}\right]=\mathcal{A}_{k}^{-1}\left(\left[\begin{array}{l}
f \\
c
\end{array}\right]+\sum_{\ell=1}^{p}\left[\begin{array}{cc}
A_{\ell} & \mathbf{0} \\
B_{\ell} & C_{\ell}
\end{array}\right]\left[\begin{array}{c}
Z_{t-\ell} \\
Y_{t-\ell}
\end{array}\right]\right)+v_{t} .
$$
}


Table 1: Sign restrictions for U.S. shocks

\begin{tabular}{|c|c|c|c|c|c|c|}
\hline Shock & $e p u_{t}^{u s}$ & $t f p_{t}^{u s}$ & $y_{t}^{u s}$ & $\pi_{t}^{u s}$ & $i_{t}^{u s}$ & $t t p_{t}^{u s}$ \\
\hline Uncertainty shock & + & ? & $?$ & ? & $?$ & ? \\
\hline Productivity shock & $?$ & + & $?$ & $?$ & $?$ & $?$ \\
\hline Aggregate demand shock & $?$ & $?$ & + & + & + & $?$ \\
\hline Cost-push shock & $?$ & $?$ & + & - & $?$ & $?$ \\
\hline Regular mon. pol. shock & $?$ & $?$ & - & - & + & - \\
\hline Bumpy mon. pol. shock & ? & ? & - & - & + & + \\
\hline
\end{tabular}

and we put no signs on the EPU index, productivity, and the Treasury term premium. For a cost-push shock, the output gap rises and the core inflation falls, and we put no signs on the responses of the remaining variables.

Regarding the monetary shocks, after a contractionary regular monetary policy shock, the short-term interest rate increases, the output gap and the core inflation fall, the slope of the Treasury term premium falls, and we put no signs on the EPU index and productivity. This is perhaps the most studied shock in SVAR analysis, and the sign restrictions we have adopted are fairly robust across a wide variety of general equilibrium models and empirical applications (see Uhlig, 2005; Canova and Paustian, 2011). For a contractionary bumpy monetary policy shock, the restrictions are the same as before, with the exception that the slope of the treasury term premium rises.

In the present analysis, we do not identify any of the structural shocks for Mexico. The reason is that we want to focus our attention on the transmission on U.S. shocks to the Mexican economy, and also we do not want to impose further restrictions that could make the signrestrictions algorithm unnecessarily slow. The only condition we impose on these shocks is that they satisfy block exogeneity, as explained above. We follow closely the procedure of Binning (2013) for imposing sign and zero restrictions, which is an extension of the RubioRamírez, Waggoner and Zha (2010) algorithm for exactly identified models to models that are underidentified. Moreover, we extend the latter procedure using the method of Arias, Rubio-Ramírez and Waggoner (2014), which properly draws from the posterior distribution of structural parameters. Both methodologies make use of the properties of the orthonor- 
mal matrices that retrieve the sign-identified models, and present a simple methodology that computes a rotation matrix that ensures that both the zero and sign restrictions are satisfied.

\section{Data}

The data set used in the estimation spans the period 2002Q1-2016Q2. For the foreign block, we use U.S. variables such as (1) the change in the EPU index by Baker et al. (2015), ${ }^{10}$ (2) the utilization-adjusted TFP growth series by Basu et al. (2006), (3) the CBO output gap, (4) the core PCE inflation, (5) the shadow Fed funds rate of Wu and Xia (2016), ${ }^{11}$ and (6) the Ten-year Treasury term premium of Adrian et al. (2013). ${ }^{12}$ The U.S. variables are obtained from the FRED2 database. Further details on these variables are presented in Appendix A.

In the foreign block we additionally assume that the change in the EPU index and in TFP are exogenous to the remaining U.S. variables. On the one hand, previous exercises where we did not assume exogeneity for the EPU index (available upon request) threw that this variable was basically explained only by its own innovation. Therefore, in this paper we assume that the EPU index is exogenous to the rest of U.S. variables. On the other hand, Basu et al. (2006) argues that other U.S. macro variables do not appear to Granger-cause their TFP measure, and so they cannot reject the exogeneity assumption. ${ }^{13}$ Nonetheless, we allow the TFP growth to respond only to an uncertainty shock. An intuition of this is found in Bloom (2009) who argues that productivity growth falls because higher uncertainty causes firms to temporary pause their investment and hiring. ${ }^{14}$

The set of foreign variables is displayed in Figure 1, and summarized in vector $Z_{t}$ as:

$$
Z_{t}=\left[\begin{array}{c}
\text { U.S. EPU index change } \\
\text { U.S. TFP growth } \\
\text { U.S. Output gap } \\
\text { U.S. Core inflation } \\
\text { U.S. Short-term interest rate } \\
\text { U.S. Treasury term premium }
\end{array}\right]=\left[\begin{array}{c}
e p u_{t}^{u s} \\
t f p_{t}^{u s} \\
y_{t}^{u s} \\
\pi_{t}^{u s} \\
i_{t}^{u s} \\
t t p_{t}^{u s}
\end{array}\right] .
$$

\footnotetext{
${ }^{10}$ This index captures the frequency of words in 10 major U.S. newspapers associated with uncertainty regarding economic policy.

${ }^{11}$ This rate coincides with the federal funds before and after the ZLB from July 2009 to December 2015

${ }^{12}$ According to Canova (2005) the slope of the yield curve has higher predictive power for real activity and inflation than the short-term interest rate. Additionally, this variable helps us to capture the monetary policy shocks during the ZLB.

${ }^{13}$ Basu et al. (2006) use the same variables that in our foreign block, except for the EPU index and core inflation, among others.

${ }^{14}$ Despite this negative correlation, we impose no sign on the response of TFP to an uncertainty shock as can be seen in Table 1 .
} 
Figure 1: Data used in the estimation of the reduced-form VAR
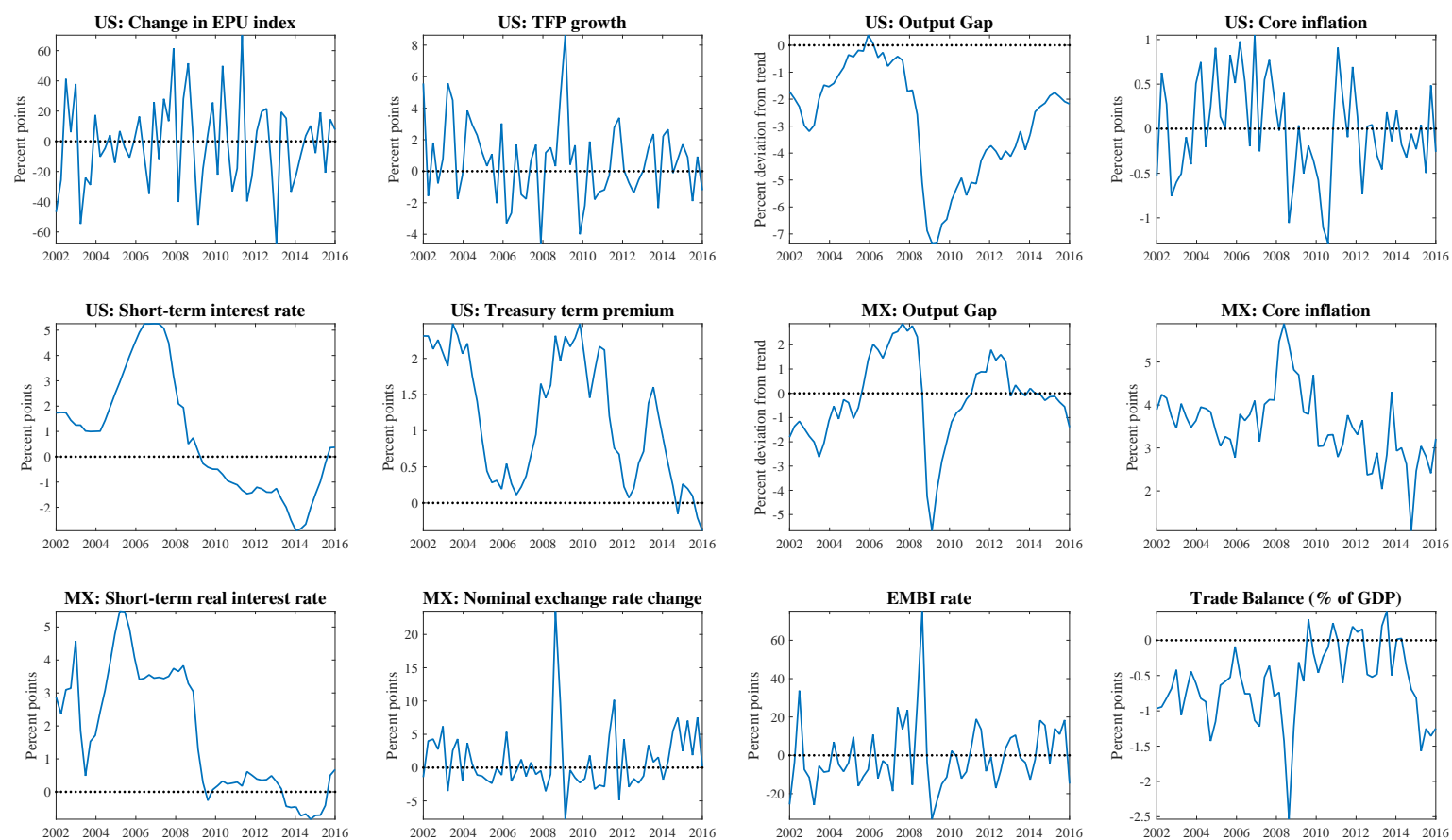

Note: All domestic variables were extracted from INEGI and Banco de México. For U.S. variables, we used the FRED2 database.

For the domestic block, we use Mexican variables such as (1) the output gap, (2) the core CPI inflation, (3) the short-term real interest rate, and (4) the change in the nominal exchange rate, (5) the EMBI rate, and (6) the trade balance as a percentage of GDP. These variables are explained in detail in Appendix A. We use core inflation since headline inflation measure is more volatile and subject to temporary shocks that are beyond the control of the central bank, e.g. bad weather conditions on agriculture. All domestic variables were obtained from either INEGI (the Mexican National Bureau of Statistics) or Banco de México, at a quarterly frequency. The set of domestic variables is portrayed as well in Figure 1, and summarized in vector $Y_{t}$ as:

$$
Y_{t}=\left[\begin{array}{c}
\text { MX Output gap } \\
\text { MX Core inflation } \\
\text { MX Short-term real interest rate } \\
\text { MX Nominal exchange rate change } \\
\text { MX EMBI rate } \\
\text { MX Trade balance (\% of GDP) }
\end{array}\right]=\left[\begin{array}{c}
y_{t} \\
\pi_{t} \\
r_{t} \\
\Delta s_{t} \\
e m b i_{t} \\
t b_{t}
\end{array}\right]
$$




\section{Results}

In this section, we apply the identifying assumptions discussed above to study the effects of aggregate U.S. shocks on Mexico. As discussed in the introduction, the relationship between Mexico and the U.S. economies is tight, with a correlation between the Mexican output gap and the U.S. output gap of about 86 percent for the sample period considered. Also, the main trading partner of Mexico is the U.S., where over 80 percent of the Mexican exports are sold. Further, Mexico is about 9 times smaller in terms of annual GDP than its North-American neighbour. Given these characteristics, it seems reasonable to assume that the U.S. business cycle affects that of Mexico, but not vice versa, i.e., U.S. aggregate dynamics are exogenous to Mexican aggregate dynamics. We identify U.S. shocks following the Binning (2013)'s sign and zero restrictions procedure along with the method of Arias et al. (2014).

\subsection{Estimation of the reduced-form VAR}

The reduced-form VAR is estimated by using Bayesian methods with Minnesota-type priors previously selected for the U.S. variables, and 4 lags. We also incorporate priors about the long-run behavior of the variables included in the VAR following Villani (2009)'s procedure.

For the selection of the Minnesota priors and the lag length in the reduced-form VAR, we considered only the foreign block. The reason why we do so is because we want the VAR to fit U.S. dynamics as good as possible. Thus, we estimated two VAR models, one with 2 lags and another with 4 , and incorporated steady state-priors for the intercepts of the VAR. ${ }^{15}$ For each model, the prior tightness is selected by comparing the marginal likelihood, computed as in Chib (1995), for a set of different hyperparameters. ${ }^{16}$ The estimation is based on a Gibbs sampling algorithm adjusted by Villani (2009) to take into consideration the imposed steadystate priors, where we saved the final 1,000 draws out of a total of 20,000, and then computed the marginal likelihood, in each case. We slightly modified the Minnesota prior variance to take into account the block-exogeneity assumption exposed above. A computation of the

\footnotetext{
${ }^{15}$ For the U.S. variables we take the following prior for the long-run means: a steady-state value of 0 for the outgap, $2 \%$ for the core inflation, and $3 \%$ for the short-term interest rate, while for the change in the EPU index, the change in TFP, and the treasury term premium we take their sample average as their steady-state values.

${ }^{16}$ For this, we created a grid assigning the $\lambda_{i}$ 's, $i=0,1,2$, different values. We tried with $\lambda_{0}=[0.001: 0.5$ : $3], \lambda_{1}=[0.1: 0.1: 1], \lambda_{2}=[0.1: 0.1: 1], \lambda_{3}=1$, and $\lambda_{4}=10^{4}$, where $\lambda_{0}$ denotes the tightness of the prior variance for the long-run means. This provides a total of 700 alternative specifications. We chose the quartet of $\lambda \mathrm{s}$ that maximize the marginal likelihood of the model.
} 
Bayes Factor does not find evidence that 4 lags is better than $2 .{ }^{17}$ However, model 2 shows a better performance when forecasting long-run values of the variables and, therefore, we selected this model for our estimates. ${ }^{18}$

We found that the best Minnesota priors for the U.S. variables are $\lambda_{0}=0.001, \lambda_{1}=0.3$, $\lambda_{2}=0.1, \lambda_{3}=1$, and $\lambda_{4}=10^{4}$. We use these priors in the estimation of the reducedVAR with both foreign and domestic variables incorporating as well steady-state priors for the latter ones in the Gibbs sampling algorithm, and again saved the final 1,000 draws out of a total of $20,000 .{ }^{19}$

\subsection{Impulse Responses to the U.S. identified shocks}

Sign restrictions do not require any variable ordering to identify shocks. Given a draw from the posterior distribution of the reduced-form parameters, we use the algorithm of Binning (2013) along with the method of Arias et al. (2014) to collect 5000 draws from the posterior distribution of the structural parameters that satisfy our zero and sign restrictions. Each draw is randomly selected from a uniform distribution over the range of the posterior distribution of the reduced-form parameters. We impose zero and sign restrictions for the foreign variables' responses only in the impact period to six types of shocks mentioned above (see Table 1). Then, we analyze the effect of these U.S. shocks on Mexican variables.

On the other hand, we are interested in ruling out implausible large responses of inflation on impact after monetary policy shocks. Jääskelä and Jennings (2011) and Carrillo and Elizondo (2015) document that these large implausible responses on inflation may appear in monetary SVAR models with sign restrictions. In preliminary exercises, we included thus a cap on the impact response of U.S. core inflation after the monetary shocks, which builds on an estimation of the interest-rate elasticity of inflation (for further details, see Carrillo and Elizondo, 2015). However, we still found a response on impact of core inflation to monetary shocks. Adding this restriction significantly slows the estimation process, and therefore, we did not include it in the estimates shown below. The impulses responses in the figures below

\footnotetext{
${ }^{17}$ The best priors for model 1 and model 2 yielded a marginal likelihood of -486.88 and -486.30 , respectively. Kass and Raftery (1995) recommend the interpretations of intervals of values of the Bayes factor.

${ }^{18}$ A good summary of how to implement the algorithms of Villani (2009) and Chib (1995) can be found in Blake and Mumtaz (2012).

${ }^{19}$ For the Mexican variables, the prior for the long-run means is: 0 for the output gap, $3 \%$ for the core inflation (inflation target), $2.5 \%$ for the short-term real interest rate, and the sample average for the change in the nominal exchange rate, the EMBI rate, and the trade balance (\% of GDP).
} 
display the median of the distribution as well as the central 68th and 90th percentiles of the impulse responses.

Figure 2 shows the impulse responses of U.S. and Mexican variables to an uncertainty shock. The shock is identified for the U.S. variables according to the signs of Table 1. In this case, there is a fall in the TFP growth and after three quarters there is a rebound to then come back to its steady state. Interestingly, Bloom (2009) finds a similar result in his model. There is also a fall in the U.S. output and prices, and as a result of this activity contraction, the monetary authority reacts by lowering the short-term interest rate, while investors before a climate of uncertainty will demand higher long-term interest rates, and therefore, there is an increase in the Treasury term premium. As regards the domestic economy, there is a rise in the EMBI index and a fall in the trade balance causing in turn a depreciation in the nominal exchange rate and inflationary pressures. As a consequence, the central bank reacts by increasing the short-term interest rate, which causes a fall in the Mexican output for a few periods. Nonetheless, a variance decomposition indicates that the uncertainty shock does not play an important role in explaining the variability of the Mexican output and core inflation (see Figure 8).

Figure 3 shows the impulse responses to a positive productivity shock. This shock is identified according to our sign restrictions imposed in Table 1. In this case, the U.S. output and the short-term interest rate increase. There is a permanent effect on prices which slightly increases respect with its steady state at least at a $68 \%$ level of confidence. The response of the Treasury term premium is not significant at a $68 \%$ level of confidence. The EPU index does no respond to this shock as expected. As for the domestic economy, the increase in the U.S. TFP growth in the U.S. causes capital outflows in Mexico (not shown here), and therefore, there is a contraction in the economic activity. The responses of the nominal exchange rate and inflation are not significant at a $68 \%$ level of confidence. The central bank, as a consequence, would react by lowering the short-term interest rate.

Figure 4 exhibits the impulse responses to a positive aggregate demand shock. This shock is identified according to our sign restrictions imposed in Table 1. For the U.S. variables, the output gap, the core inflation, and the short-term interest rate increase. In response to this expansion, the risk aversion and premium decrease which is reflected in the response of the Treasury term premium. The EPU index and the TFP do not respond to this shock as expected. The positive demand shock increases as well the U.S. demand for Mexican products causing a rise in the trade balance and, therefore, there is a rise in the Mexican 
Figure 2: Impulse responses to an uncertainty shock


Note: The figure reports the median impulse response computed from the 5000 posterior draws of the structural parameters satisfying our zero and sign restrictions, as well as the central 68th and 90th percentiles of the distribution of the impulse responses in different shades. 
Figure 3: Impulse responses to a positive productivity shock


Note: The figure reports the median impulse response computed from the 5000 posterior draws of the structural parameters satisfying our zero and sign restrictions, as well as the central 68th and 90th percentiles of the distribution of the impulse responses in different shades. 
output, an appreciation in the exchange rate, and a fall in prices for a few periods. The EMBI index falls in response to this economic expansion. Before this situation the respective central banks react by increasing the short-run real interest rate.

Figure 4: Impulse responses to a positive aggregate demand shock
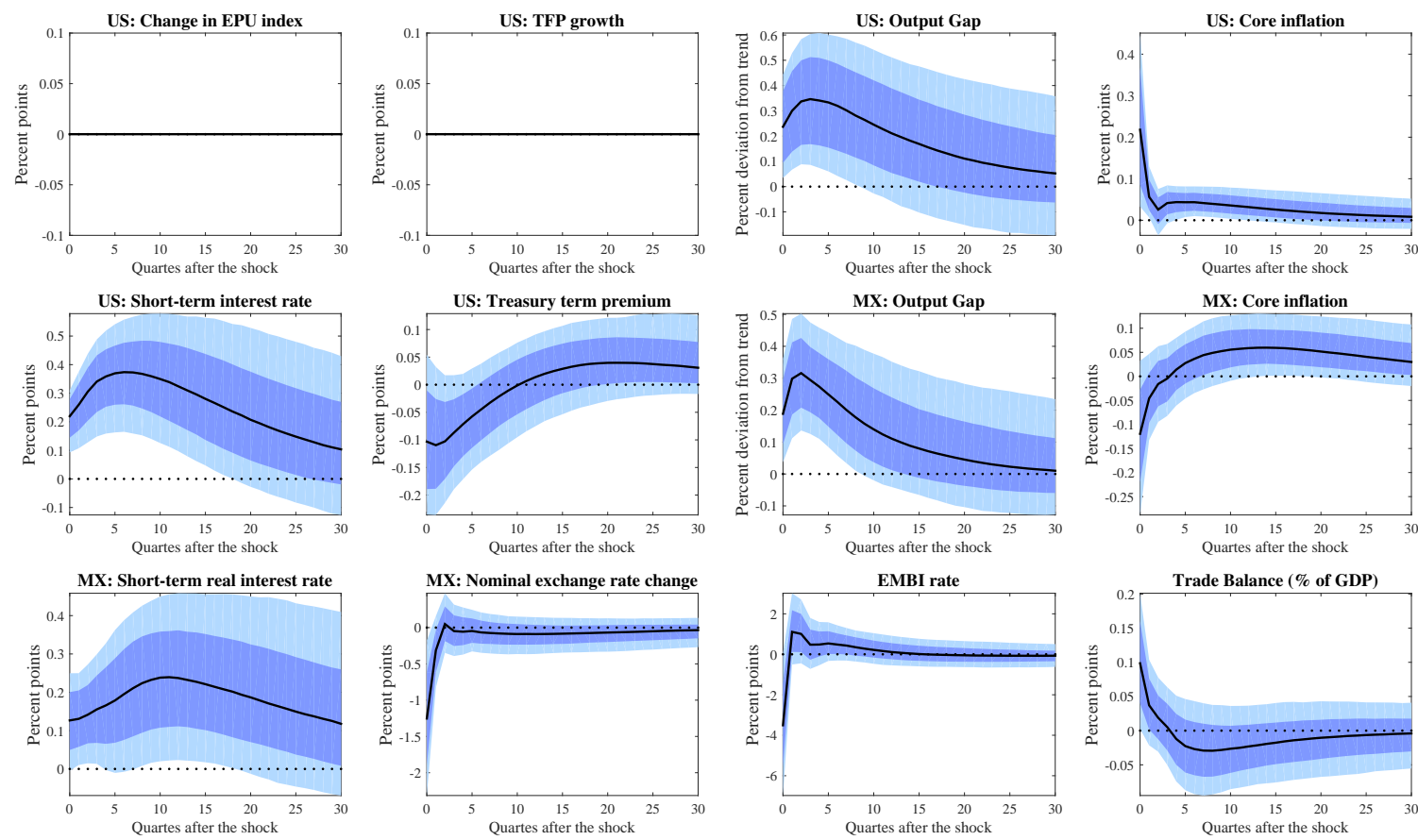

Note: The figure reports the median impulse response computed from the 5000 posterior draws of the structural parameters satisfying our zero and sign restrictions, as well as the central 68th and 90th percentiles of the distribution of the impulse responses in different shades.

Figure 5 shows the responses to a cost-push shock. The EPU index and productivity remain unchanged as expected. There is an increase in the U.S. output and a fall in core inflation. The responses of the short-term interest rate and the Treasury term premium are not significant at a $68 \%$ level of confidence, which reflects that there is no reaction from the central bank. As for the domestic economy, there are no significant responses of the Mexican variables, except for prices which fall for a few periods. A variance decomposition shows that the cost-push shock does not play an important role in explaining the variability of the Mexican variables (see Figure 8).

Figure 6 shows the responses to a regular monetary policy shock. In this case, an increase in the U.S. short-term interest rate produces a contraction in activity, a (short) fall in prices and in the Treasury term premium. The EPU index and TFP satisfy the block-exogeneity assumption. In the domestic economy, there is also a contraction in activity due to a fall in 
Figure 5: Impulse responses to cost-push shock


Note: The figure reports the median impulse response computed from the 5000 posterior draws of the structural parameters satisfying our zero and sign restrictions, as well as the central 68th and 90th percentiles of the distribution of the impulse responses in different shades. 
the trade balance yielding to a depreciation in the nominal exchange rate. The weak demand seems to compensate the effect of the pass-through of the exchange rate and the response of prices is not significant. These results indicate that there is no a response of the domestic central bank at least for two periods, and then it decreases the interest rate. There is a similar response of the EMBI index. Interestingly, there is no an observed co-movement in the U.S. and Mexican interest rates.

Figure 6: Impulse responses to a regular monetary policy shock


Note: The figure reports the median impulse response computed from the 5000 posterior draws of the structural parameters satisfying our zero and sign restrictions, as well as the central 68th and 90th percentiles of the distribution of the impulse responses in different shades.

Finally, Figure 7 displays the impulse responses to a bumpy monetary policy shock. An increase in the U.S. short-term interest rate produces an activity contraction, a fall in prices for a few quarters, and a rise in the Treasury term premium. The EPU index and TFP do not respond to this shock. In the domestic economy, this shock produces a decrease in the trade balance and, therefore, a fall in the Mexican output gap and a depreciation in the exchange rate. There are inflationary pressures and there is no reaction from the central bank (the response of the short-term of the interest rate is not significant). In this case the EMBI index increases on impact. Under a bumpy monetary policy shock the effects on the domestic economy are more damaging than under a regular one. 
Figure 7: Impulse responses to a bumpy monetary policy shock


Note: The figure reports the median impulse response computed from the 5000 posterior draws of the structural parameters satisfying our zero and sign restrictions, as well as the central 68th and 90th percentiles of the distribution of the impulse responses in different shades. 


\subsection{Variance decomposition}

In this section, we measure what the contribution of each shock is to explain the variance of the U.S. and Mexican variables in the long run. Figure 8 shows the variance decomposition for these variables in terms of the shocks identified for the U.S. and Mexican shocks. The estimation corresponds to the model closest to the median of the distribution of the impulse responses. ${ }^{20}$ Similar information can be drawn from Tables 2 to 4 , which show the mean and median proportion of a variable's variance explained by each shock. We present the measure for the median of all sign-identified models as well as for the model that is closest to the median impulse responses.

Regarding the U.S. variables, the change in the EPU index is explained by its own shock by assumption; in turn, $90 \%$ of the variability in the TFP growth is explained by its own shock, while $10 \%$ is explained by the uncertainty shock. The aggregate demand and the uncertainty shocks are the main drivers of the output gap and the short-term interest rate, and together explain up to $85 \%$ of their fluctuations. The main driver of the core inflation is the cost-push shock and explains around $50 \%$ of its variability, while the Treasury term premium is mainly explained by the bumpy monetary policy shock whose contribution is around $40 \%$. As expected, Mexican shocks play no role in explaining U.S. fluctuations.

On the other hand, U.S. shocks play an important role in explaining the long-run variability of Mexican variables. Around $70 \%$ and $80 \%$ of the long-run volatility of the Mexican output gap and the short-term real interest rate can be explained by U.S. structural shocks, respectively. The shock to U.S. aggregate demand is the main driver of the output gap explaining around $40 \%$ of its variability. For the short-term real interest rate, the U.S. aggregate demand and the uncertainty shocks are the main drivers and explain up to $20 \%$ and $40 \%$ of its fluctuations, respectively. U.S. cost-push shocks are not significantly transmitted across Mexican variables. In turn, U.S. shocks explain around $60 \%$ of the long-run variability of the core inflation. The EPU shock does not play a significant role in driving the output gap and the core inflation. However, this shock in one of the main drivers of the change in the nominal exchange rate, the EMBI rate, and the trade balance and explains around 30\%, 20\%, and $25 \%$ of its fluctuations, respectively.

\footnotetext{
${ }^{20}$ We follow Fry and Pagan (2011)'s Median Target Method whose solution is to choose a model that produces impulse responses as close to the median responses as possible.
} 
Figure 8: Variance decomposition of U.S. and Mexican variables in terms of U.S. and Mexican shocks
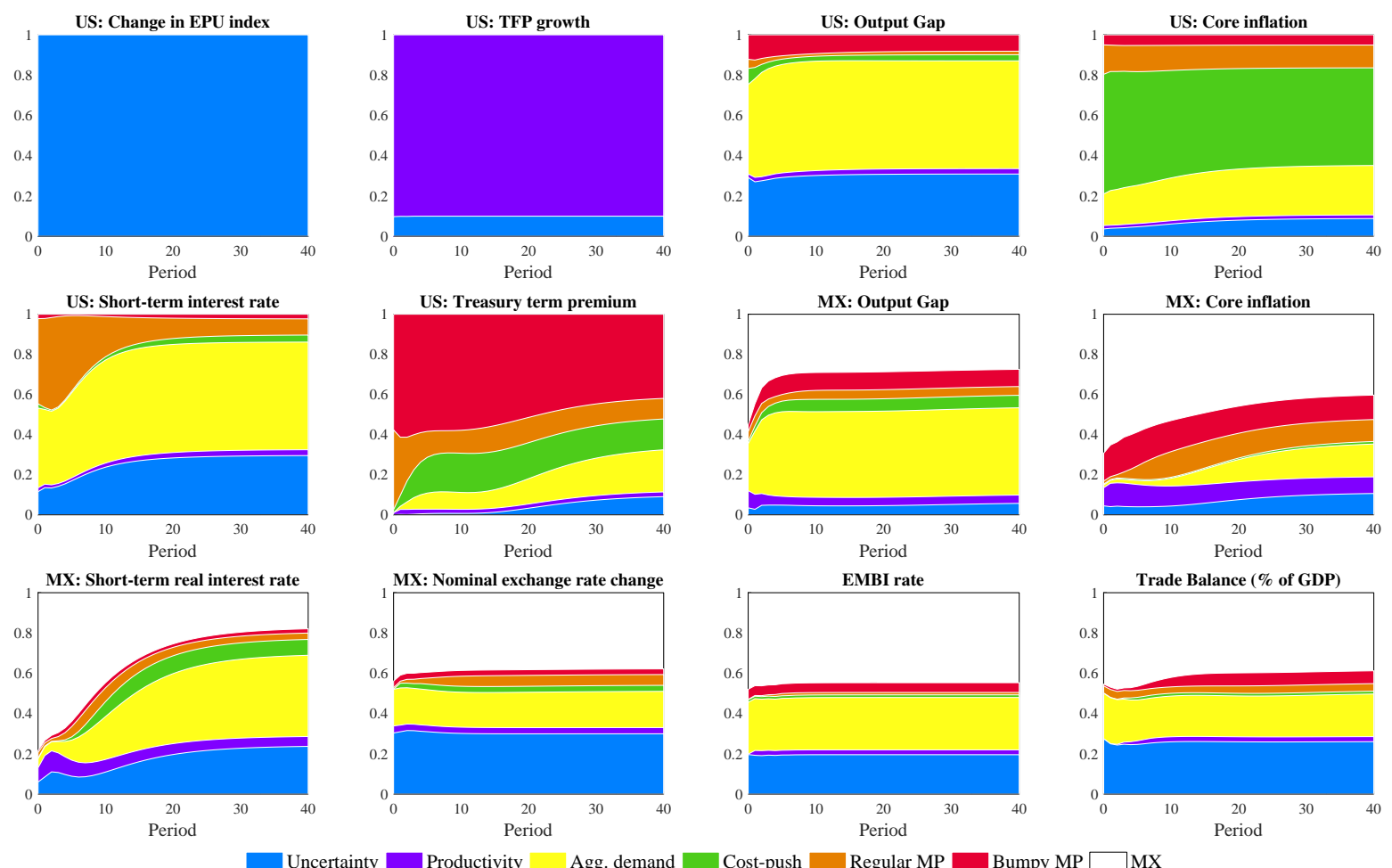

Note: The estimation corresponds to the model closest to the median of the distribution of the impulse responses. 


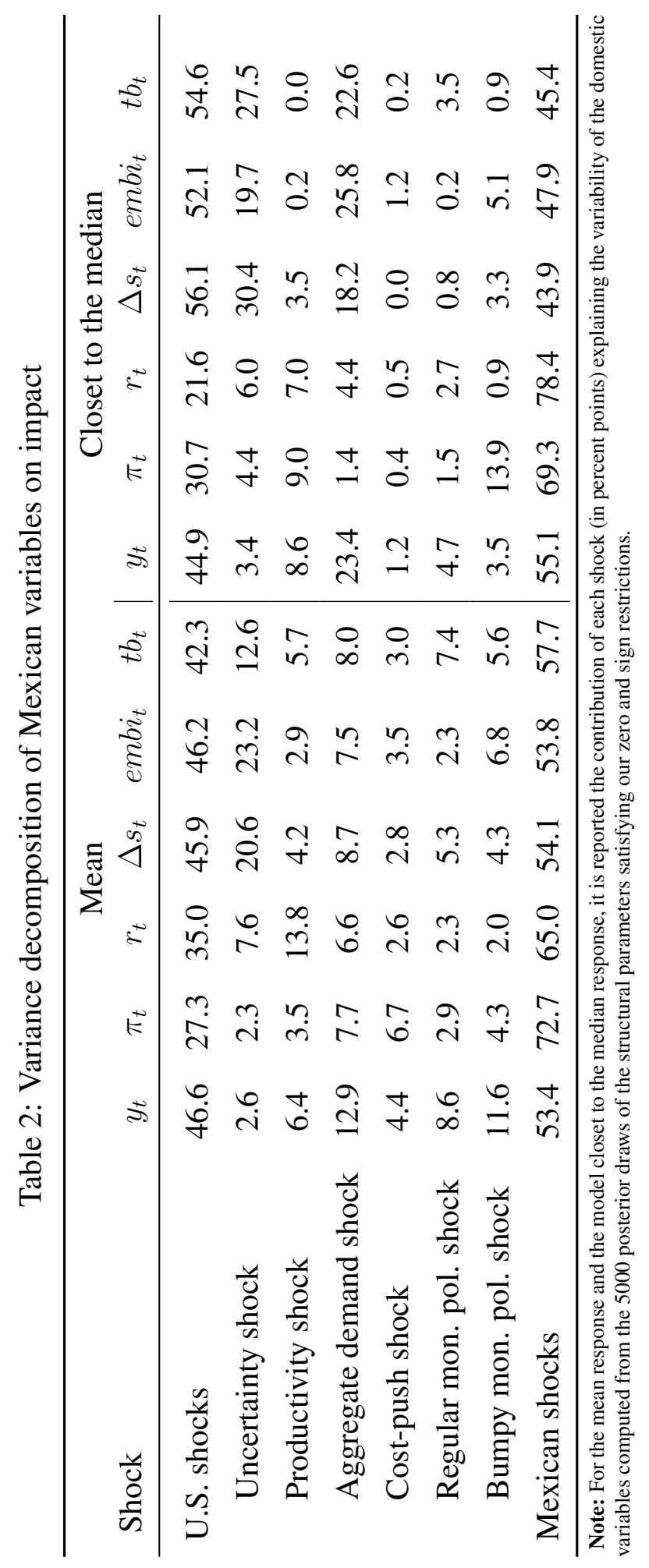









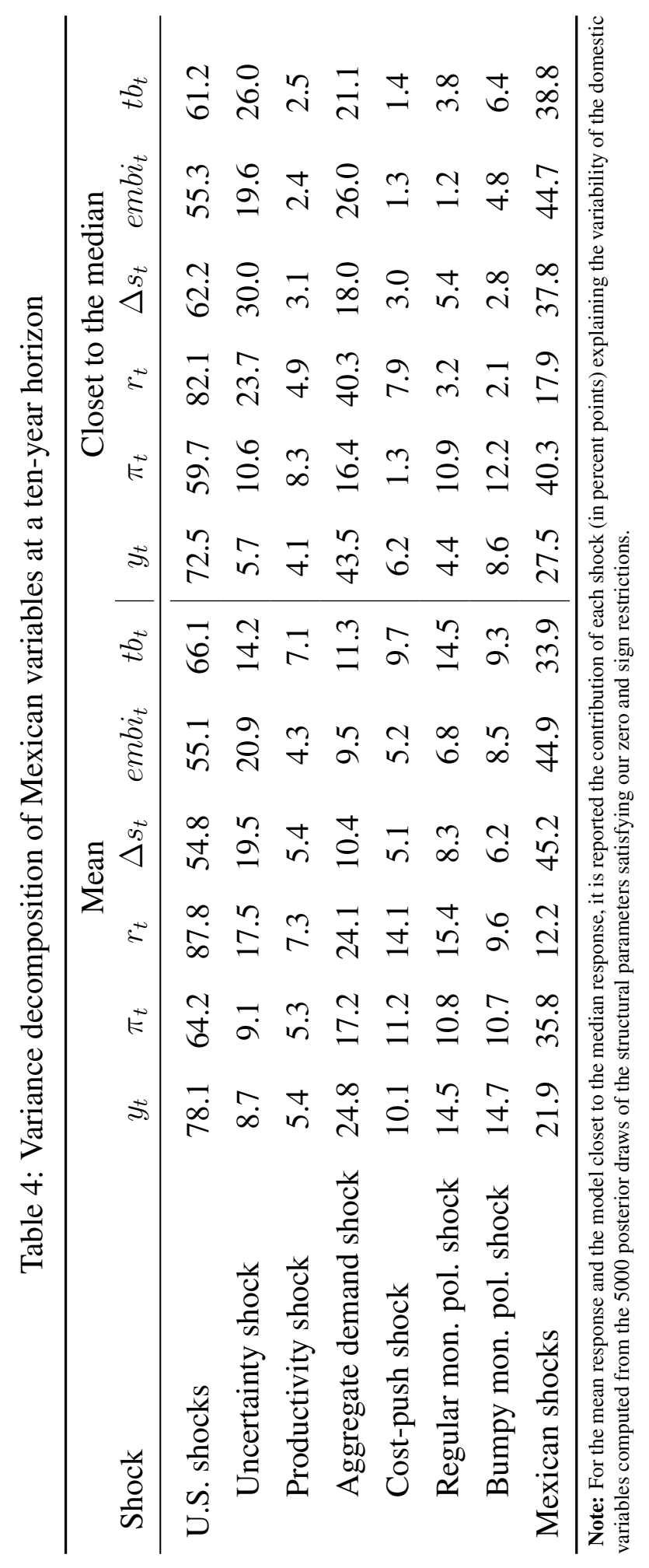




\subsection{Historical Decomposition and Counterfactual Exercises}

In Figure 9 we display the historical decomposition of the data which shows the contribution of each shock to the fluctuations of U.S. and Mexican variables over the sample period. This decomposition is done using the model closets to the median response, and whose variance decomposition is shown in Figure 8. The results show that the decline in the U.S. output gap in the onset of the financial crisis in 2008 is mainly explained by the aggregate demand shock. In turn, this shock also explains the decline in the Mexican output gap during the Great Recession. Similarly, as of 2008 the aggregate demand shock mostly explains the path in the U.S. and Mexican policy interest rates. The U.S. core inflation is mainly explained by cost-push shocks, while the Mexican core inflation is mainly explained by domestic shocks

over the same period. The U.S. Treasury term premium is mainly explained by the monetary shocks, and after the crisis the aggregate demand shock starts to take a major relevance. Finally, domestic shocks and the EPU shock mainly explain the path of the nominal exchange rate, the EMBI rate, and the trade balance (\% of GDP) over the sample period. Moreover, for the latter two variables the aggregate demand shock starts to take a major relevance after the Great Recession.

As it can be seen in Figure 9, our SVAR results point that the 2008 financial crisis was largely driven by the U.S. aggregate demand shock, and to a lesser extent by contractionary monetary policy shocks. Recall that we are using the shadow policy rate of $\mathrm{Wu}$ and Xia to measure U.S. monetary policy. This rate became negative after 2009 to map the effects of the Fed's unconventional monetary policy in the aftermath of the crisis. As these measures are imperfect substitutes of changes in the fed funds rate, the SVAR interprets that the Fed's monetary accommodation during this period was insufficient, reflecting partially the ZLB constraint faced by the Fed. In view of these results, we use the identified SVAR model to perform two counterfactual experiments. First, we ask what would have been if there was no negative aggregate demand shocks from 2008Q2 onwards. And second, we ask what would have happened if the contractionary monetary policy shocks had never existed after the default of Lehman.

Figure 10 compares actual and counterfactual paths of the variables in the absence of the U.S. negative aggregate demand shock from 2008Q2-2016Q2. The results indicate that the fall in the output gap both in the U.S. and Mexico would had been lower, especially in the U.S. 
A major U.S. demand for imports explains the rise in the Mexican output gap. The increase in the core inflation would have been milder in Mexico than in the U.S. As a consequence, the policy rates in each country would have increased, implying a reduction in the Treasury term premium in the U.S. from 2008-2011 and an increase afterwards. This scenario does not seem to have a significant effect on the rest of the variables. In turn, the paths for the second counterfactual exercise are shown in Figure 11. The results suggest that the recession in the aftermath of the crisis in both U.S. and Mexico would have not been as deep if the Fed had not faced the ZLB constraint in the fed funds rate. However, the duration of the crisis would have remained the same. It is worth mentioning that these exercises are subject to the Lucas critique, since they assume agent's expectations do not change, which is an unrealistic assumption. 

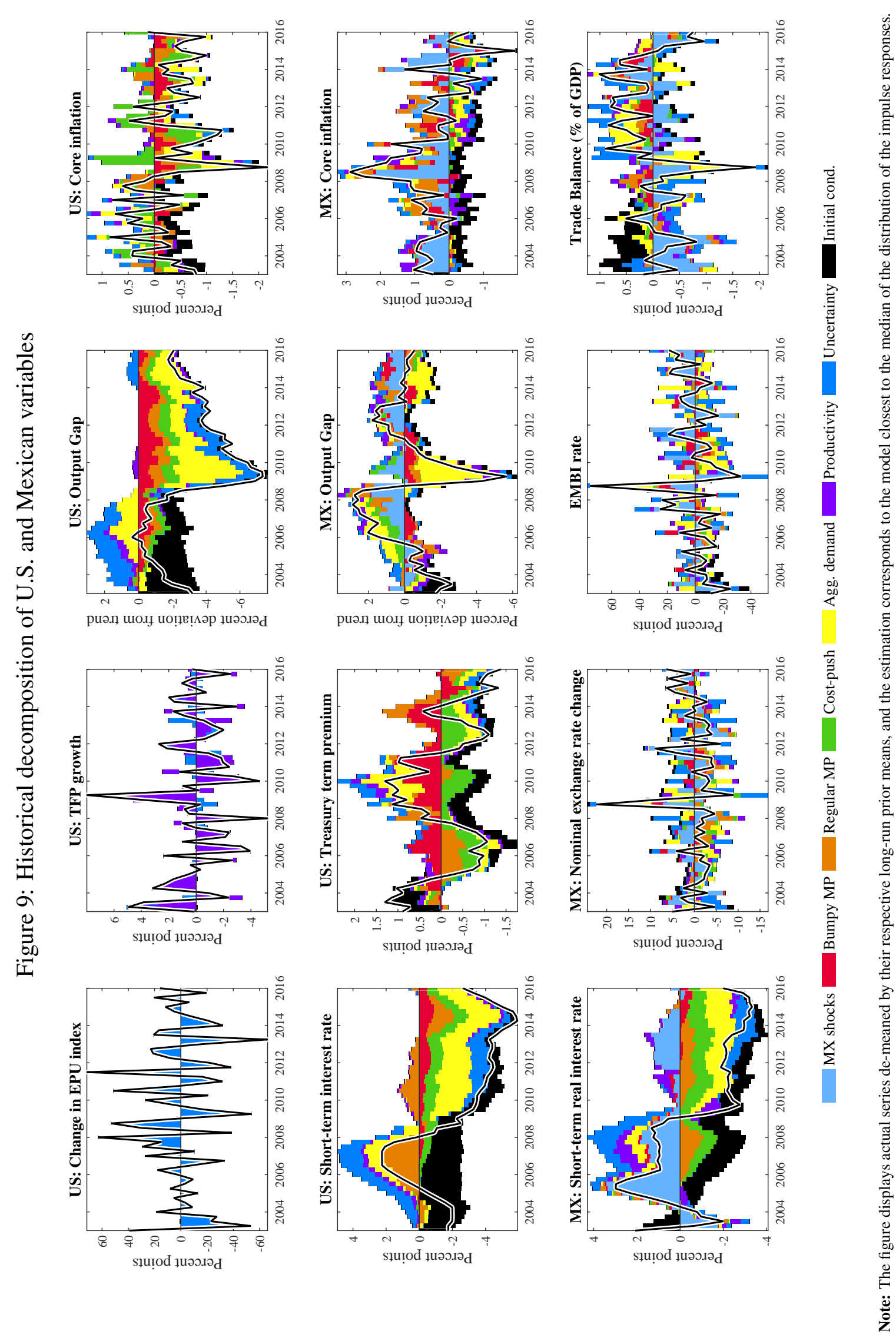
Figure 10: Counterfactual experiment: no negative aggregate demand shock (2008Q22016Q2)
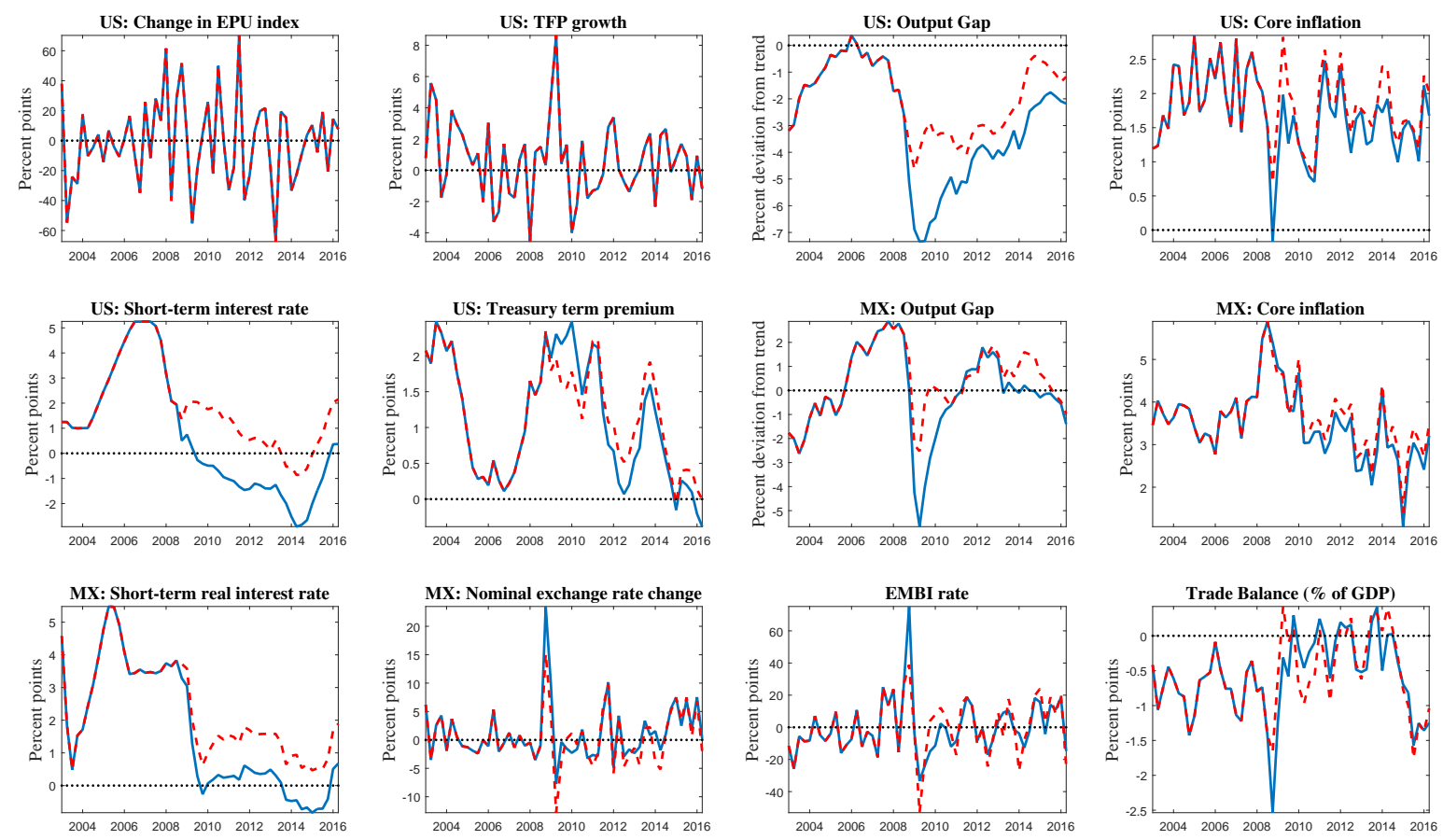

- Actual data - - - Counterfactual data

Note: The estimate of the counterfactual data correspond to the model closest to the median of the distribution of the impulse responses.

\subsection{Robustness Analysis}

In Appendix B we show the variance decomposition corresponding to the second and third models closest to the median impulse response of the exercise carried out in the previous section. As can be seen, the results are pretty similiar across the first three models closest to the median response.

On the other hand, we use a Cholesky decomposition to identify an uncertainty shock, a productivity shock, and a regular monetary policy shock in the U.S. under the order of variables given by (3) and (4). In Appendix B we show the impulse responses to these shocks. The responses to an uncertainty shock are qualitatively similar under the two approachessign and zero restrictions and Cholesky - (compare Figures 2 and B.3). The responses to a positive productivity shock are very similar under the two approaches as well (compare 
Figure 11: Counterfactual experiments: no monetary shocks (2008Q2-2016Q2)
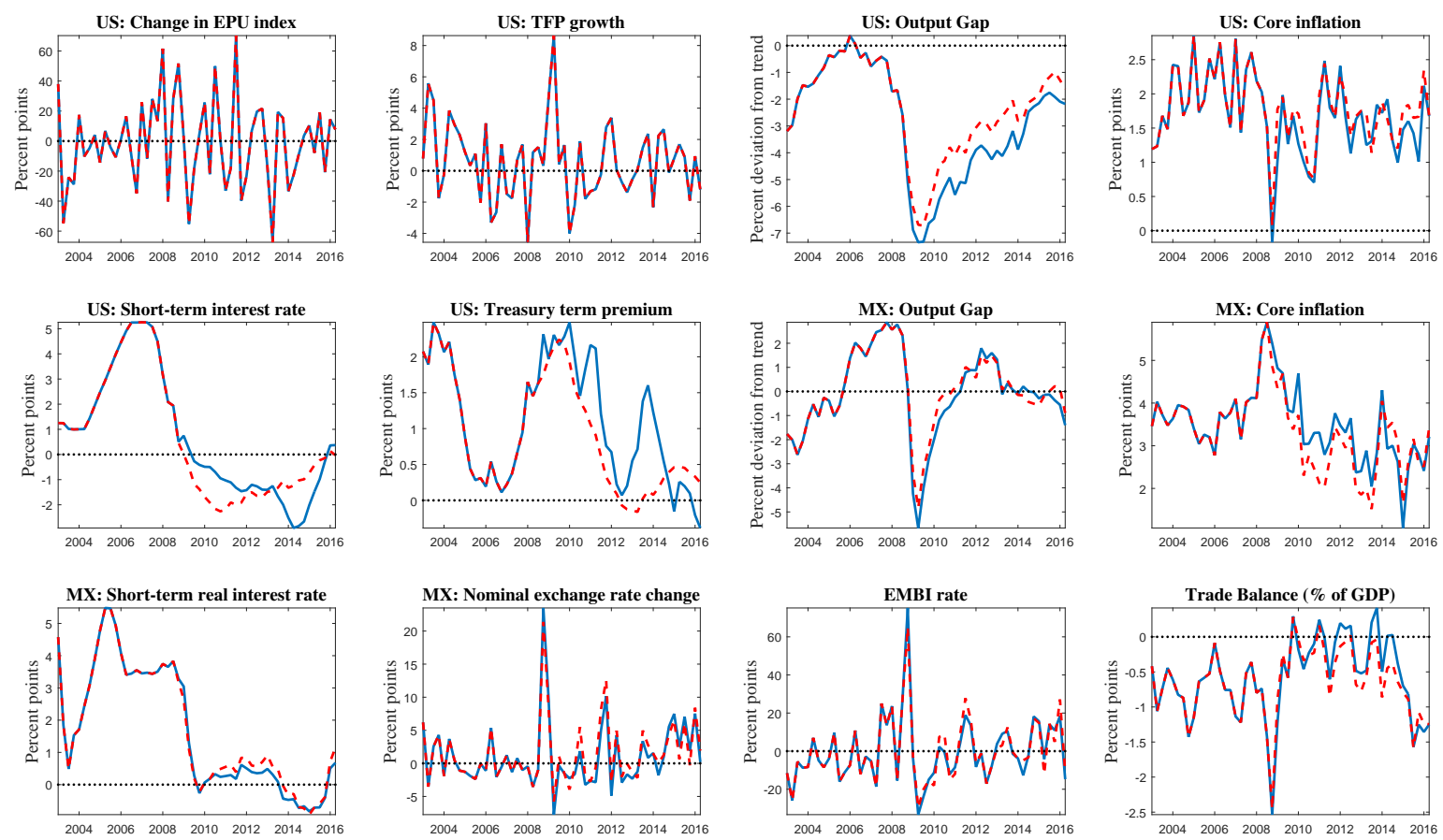

Note: The estimate of the counterfactual data correspond to the model closest to the median of the distribution of the impulse responses. 
Figures 3 and B.4). However, Cholesky identification yields price puzzling responses in the U.S. to a regular monetary shock, i.e. prices rise after a contractionary interest rate increase. Moreover, there is no a significant response of the U.S. output gap to this shock. These results suggest that the Cholesky identification does not identify properly the regular monetary policy shock and its implications are at odds with economic theory.

\section{Conclusions}

In this paper, we have studied the transmission mechanism of U.S. aggregate shocks to the Mexican economy. In a SVAR model for a small open economy, we used a combination of sign and zero restrictions to identify six types of U.S. shocks: an uncertainty shock, a productivity shock, an aggregate demand shock, a cost-push shock, and two types of monetary policy shocks in the U.S., and characterized their transmission to the Mexican economy over the period 2002Q1-2016Q2. We imposed block-exogeneity between Mexican and U.S. variables, so that neither Mexican shocks nor variables significantly affect the behavior of U.S. variables.

Our approach provides results that are in line qualitatively with impulse responses from a vast class of DSGE models with nominal rigidities. We find that around $80 \%$ of the long-run volatility of the Mexican output gap can be explained by U.S. structural shocks. The shock to U.S. aggregate demand is the main driver of the output gap explaining around $25 \%$ of its variability. For the short-term real interest rate, the U.S. aggregate demand and the uncertainty shocks are the main drivers and explain up to $25 \%$ and $18 \%$ of its fluctuations, respectively. U.S. cost-push shocks are not significantly transmitted across Mexican variables. In turn, U.S. shocks explain around $60 \%$ of the long-run variability of the core inflation. The EPU shock does not play a significant role in driving the output gap and the core inflation. However, this shock is one of the main drivers of the change in the nominal exchange rate, the EMBI rate, and the trade balance and explains between $15 \%$ and $20 \%$ their fluctuations.

The uncertainty surrounding future economic policies in the world is a new factor that can influence bilateral relations between countries, as well as the behavior of their economies. In this context, a topic that arises for monetary policymakers is to analyze how changes in foreign conditions affect the domestic economy. It is of prime importance to provide policymakers with the best available answers to this question, so they can take the most 
appropriate decisions. In this context, we shed light on this topic for the Mexican case, which has become an emblematic one since the arrival of the new U.S. government administration. 


\section{References}

Adrian, T., Crump, R. K. and Moench, E. (2013) Pricing the term structure with linear regressions, Journal of Financial Economics, 110, 110 - 138.

Arias, J. E., Rubio-Ramírez, J. F. and Waggoner, D. F. (2014) Inference Based on SVARs Identified with Sign and Zero Restrictions: Theory and Applications, International Finance Discussion Papers 1100, Board of Governors of the Federal Reserve System (U.S.).

Baker, S. R., Bloom, N. and Davis, S. J. (2015) Measuring Economic Policy Uncertainty, NBER Working Papers 21633, National Bureau of Economic Research, Inc.

Basu, S., Fernald, J. G., and Kimball, M. S. (2006) Are Technology Improvements Contractionary?, American Economic Review, 96, 1418-1448.

Binning, A. (2013) Underidentified SVAR Models: A Framework for Combining Short and Long-run Restrictions with Sign-restrictions, Working Paper 2013/14, Norges Bank.

Blake, A. P. and Mumtaz, H. (2012) Applied Bayesian econometrics for central bankers, no. 4 in Technical Books, Centre for Central Banking Studies, Bank of England.

Bloom, N. (2009) The Impact of Uncertainty Shocks, Econometrica, 77, 623-685.

Caldara, D., Fuentes-Albero, C., Gilchrist, S. and Zakrajek, E. (2016) The Macroeconomic Impact of Financial and Uncertainty Shocks, NBER Working Papers 22058, National Bureau of Economic Research, Inc.

Canova, F. (2005) The Transmission of US Shocks to Latin America, Journal of Applied Econometrics, 20, 229-251.

Canova, F. and Paustian, M. (2011) Business Cycle Measurement with Some Theory, Journal of Monetary Economics, 58, 345-361.

Carrillo, J. A. and Elizondo, R. (2015) How Robust Are SVARs at Measuring Monetary Policy in Small Open Economies?, Working Papers 2015-18, Banco de México.

Carrire-Swallow, Y. and Céspedes, L. F. (2013) The impact of uncertainty shocks in emerging economies, Journal of International Economics, 90, 316-325.

Chen, J., Griffoli, T. M. and Sahay, R. (2014) Spillovers from United States Monetary Policy on Emerging Markets; Different This Time?, IMF Working Papers 14/240, International Monetary Fund.

Chib, S. (1995) Marginal Likelihood from the Gibbs Output, Journal of the American Statistical Association, 90, 1313-1321.

Fry, R. and Pagan, A. (2011) Sign Restrictions in Structural Vector Autoregressions: A Critical Review, Journal of Economic Literature, 49, 938-60. 
García-Verdú, S. and Ramos-Francia, M. (2014) The Transmission of US Monetary Policy Shocks to EMEs: An Empirical Analysis, Papers 78, BIS.

Hernández, K. and Leblebicioglu, A. (2015) The Transmission of U.S. Shocks to Emerging Markets, Tech. rep., Manuscript.

Jääskelä, J. P. and Jennings, D. (2011) Monetary Policy and the Exchange Rate: Evaluation of VAR Models, Journal of International Money and Finance, 30, 1358-1374.

Kass, R. E. and Raftery, A. E. (1995) Bayes factors, Journal of the American Statistical Association, 90, 773-795.

Mohanty, M. S. (2014) The Transmission of Unconventional Monetary Policy to the Emerging Markets , BIS Papers 78, Bank for International Settlements.

Rubio-Ramírez, J. F., Waggoner, D. F. and Zha, T. (2010) Structural Vector Autoregressions: Theory of Identification and Algorithms for Inference, Review of Economic Studies, 77, 665-696.

Smets, F. and Wouters, R. (2007) Shocks and Frictions in US Business Cycles: A Bayesian DSGE Approach, American Economic Review, 97, 586-606.

Takáts, E. and Vela, A. (2014) International Monetary Policy Transmission, in The transmission of unconventional monetary policy to the emerging markets (Ed.) B. for International Settlements, Bank for International Settlements, vol. 78 of BIS Papers chapters, pp. 25-44.

Uhlig, H. (2005) What Are the Effects of Monetary Policy on Output? Results from an Agnostic Identification Procedure, Journal of Monetary Economics, 52, 381-419.

Villani, M. (2009) Steady-state priors for vector autoregressions, Journal of Applied Econometrics, 24, 630-650.

Wu, J. C. and Xia, F. D. (2016) Measuring the macroeconomic impact of monetary policy at the zero lower bound, Journal of Money, Credit and Banking, 48, 253-291. 


\section{Appendix}

\section{A Data details}

This Appendix provides details of the variables used in the estimation.

Foreign block: The U.S. variables are obtained from the FRED2 database.

1. Economic Policy Uncertainty (EPU) Index. Baker et al. (2015) construct this index to measure policy-related economic uncertainty, which is based on search results from 10 U.S. large newspapers. To construct the index, they perform month-by-month searches of each paper (including human readings), starting in January of 1985, for terms related to economic and policy uncertainty. In particular, they search for articles containing the term 'uncertainty' or 'uncertain', the terms 'economic' or 'economy' and one or more of the following terms: 'congress', 'legislation', 'white house', 'regulation', 'federal reserve', or 'deficit'. Several types of evidence indicate that their index proxies for movements in policy-related economic uncertainty.

2. Measure of the TFP growth. We use the residuals from an AR(1) model of the logdifference in the utilization-adjusted TFP by Basu et al. (2006), which attempts to adjust measured TFP for a range of non-technological factors that can drive a wage between TFP and technology. The series is available at the Federal Reserve of San Francisco and the site presents a real-time quarterly series.

3. Output gap. For the U.S. potential output we use the series reported by the CBO.

4. Core PCE inflation. For this variable we compute the quarterly-by-quarterly percent change in the seasonally-adjusted Personal Consumption Expenditures Excluding Food and Energy Index.

5. The shadow rate of $\mathrm{Wu}$ and Xia (2016). This rate coincides with the federal funds before and after the zero lower bound (ZLB) from July 2009 to December 2015, and measures the effect of unconventional monetary policy at the ZLB. We calculate the quarterly average of daily data. 
6. The Treasury term premium by ACM. We use the Ten-Year Treasury Term Premium by Adrian et al. (2013) reported at the Federal Reserve Bank of New York, and calculate the quarterly average of monthly data.

Domestic block: Domestic variables are obtained from either INEGI (the Mexican National Bureau of Statistics) or Banco de México.

1. Output gap. For the Mexican potential output we used an HP-filtered with tail correction measure of the Real GDP at 2008 Mexican pesos.

2. Core CPI inflation. For this variable we use the quarterly-by-quarterly percentage change of the Core Consumer Price Index, or CPI, (inflación subyacente).

3. Short-term real interest rate. This series is computed by taking the quarterly difference between the short-term nominal interest rate and the one-year expected inflation. The short-term nominal interest rate is measured with the interest rate for Treasuries Certificates (Cetes) for 28 days.

4. The change in the nominal exchange rate. We compute the quarterly-by-quarterly percent change in the nominal exchange rate series.

5. The EMBI rate. We compute the quarterly-by-quarterly percent change in the EMBI index.

6. The trade balance as a percentage of GDP. The series is computed by using the series of the trade balance of services transformed into pesos and deflated using the CPI. Then the ratio of this series to the real GDP is taken.

Consumer prices, the output gap, and the trade balance as percentage of GDP were seasonally adjusted. The quarterly Real GDP series was originally adjusted by INEGI. For the core inflation and the trade balance as percentage of GDP we used the Additive Census X12 method. The short-term real interest rate and the change in the real exchange rate were not seasonally adjusted. 


\section{B Robustness and additional exercises}

Figures B.1 and B.2 show the variance decomposition corresponding to the second and third models closet to the median impulse responses. As it can be seen, the results are pretty similar across these models.

Finally, the responses to an uncertainty shock, a productivity shock, and a regular monetary policy shock using a Cholesky identification are shown in Figures B.3, B.4, and B.5, respectively.

Figure B.1: Variance decomposition of U.S. and Mexican variables in terms of U.S. and Mexican shocks
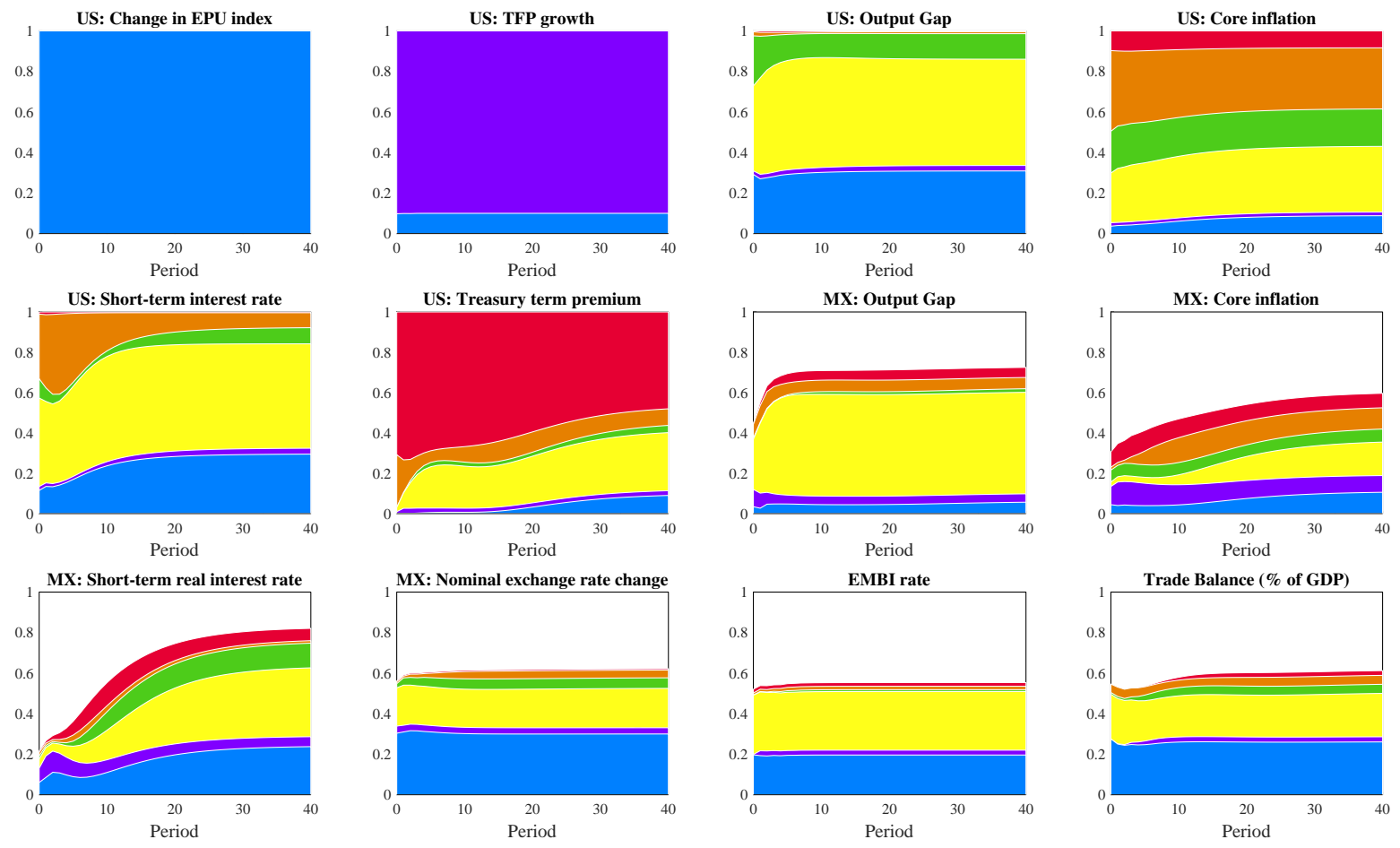

Note: The estimation corresponds to the model closest to the median of the distribution of the impulse responses. 
Figure B.2: Variance decomposition of U.S. and Mexican variables in terms of U.S. and Mexican shocks
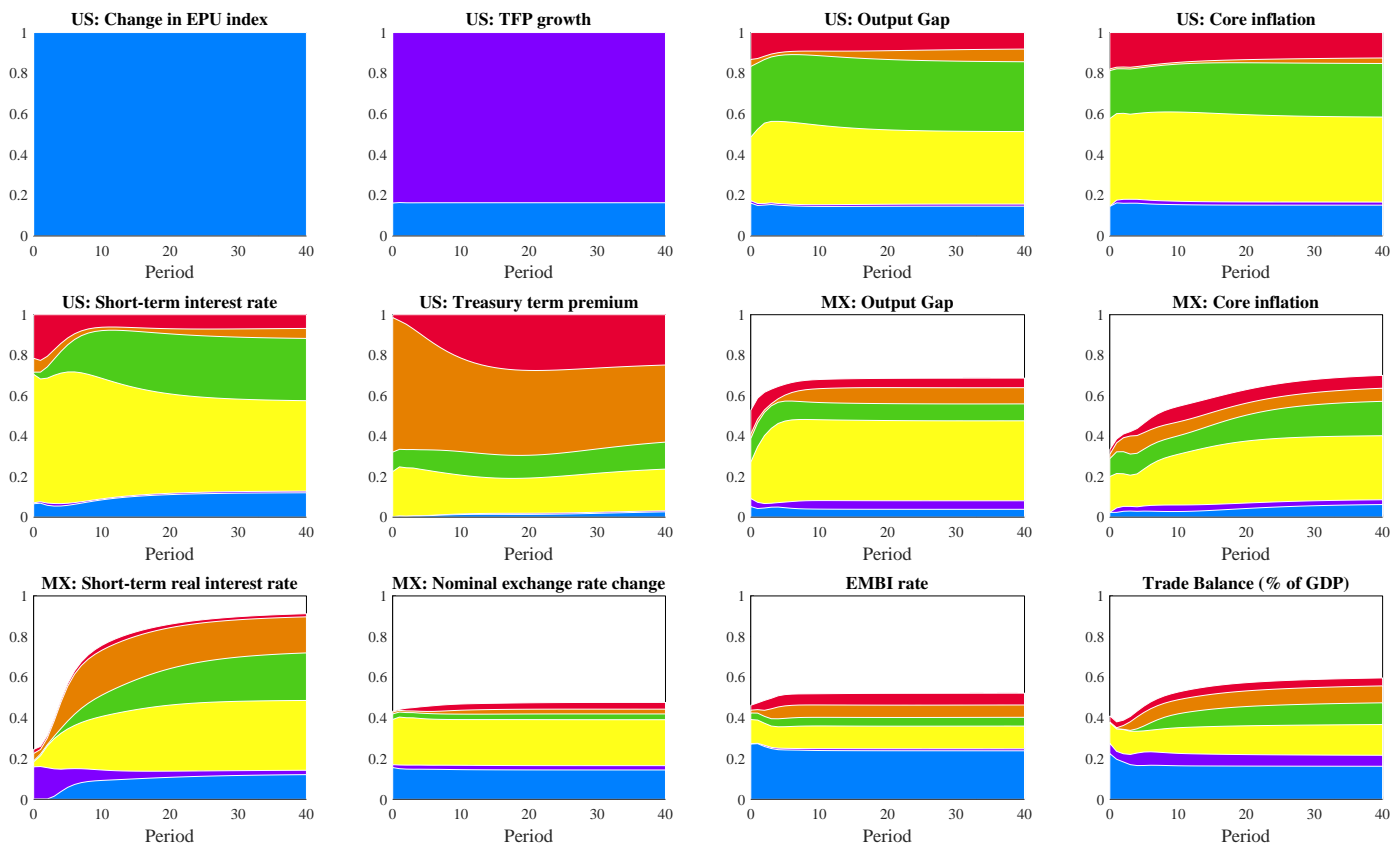

$\square$ Uncertainty $\square$ Productivity $\quad$ Agg. demand $\square$ Cost-push $\square$ Regular MP $\square$ Bumpy MP $\square$ MX

Note: The estimation corresponds to the model closest to the median of the distribution of the impulse responses. 
Figure B.3: Impulse responses to an uncertainty shock using a Cholesky identification
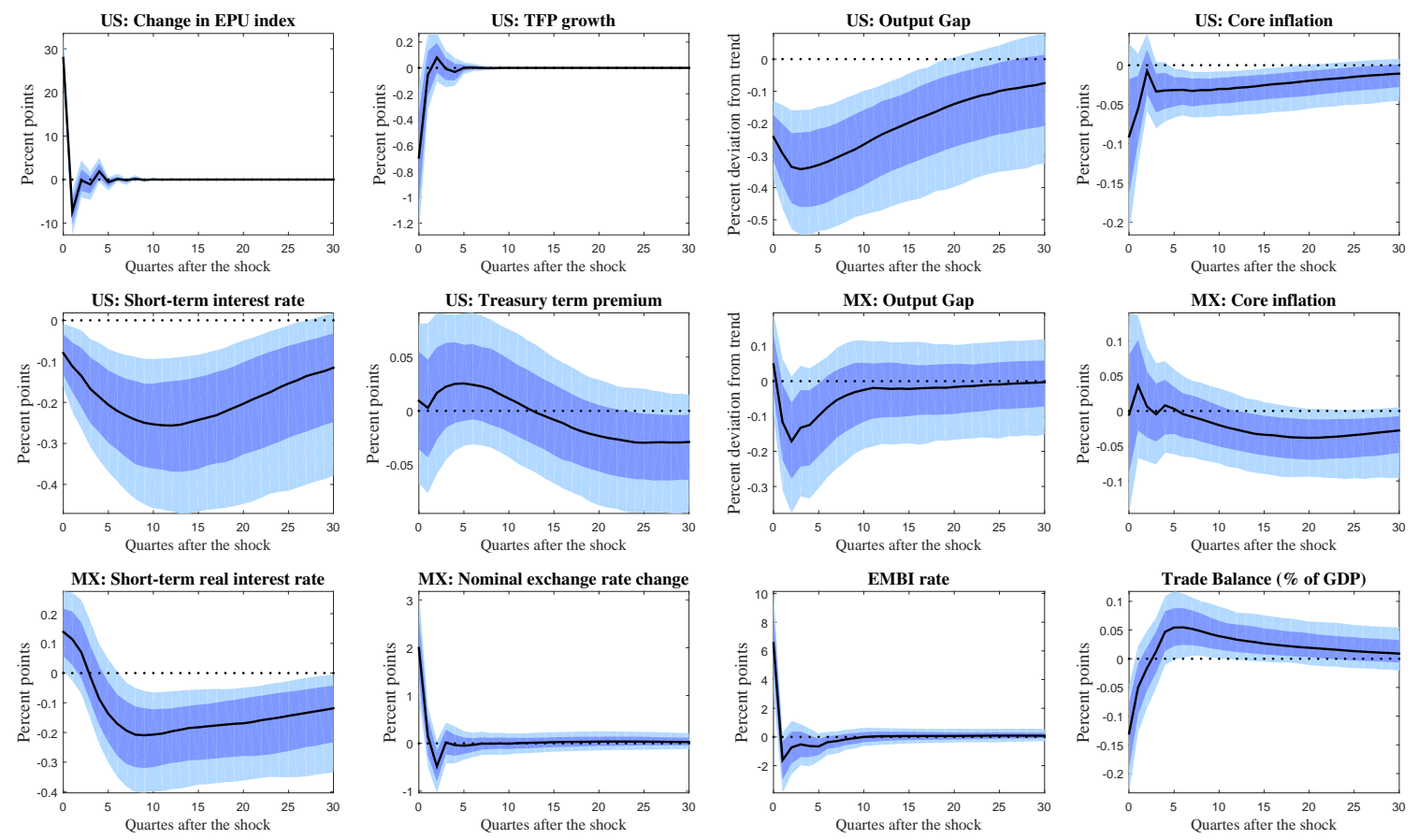

Note: The figure reports the median impulse response as well as the central 68th and 90th percentiles of the distribution of the impulse responses in different shades. 
Figure B.4: Impulse responses to a positive productivity shock using a Cholesky identification
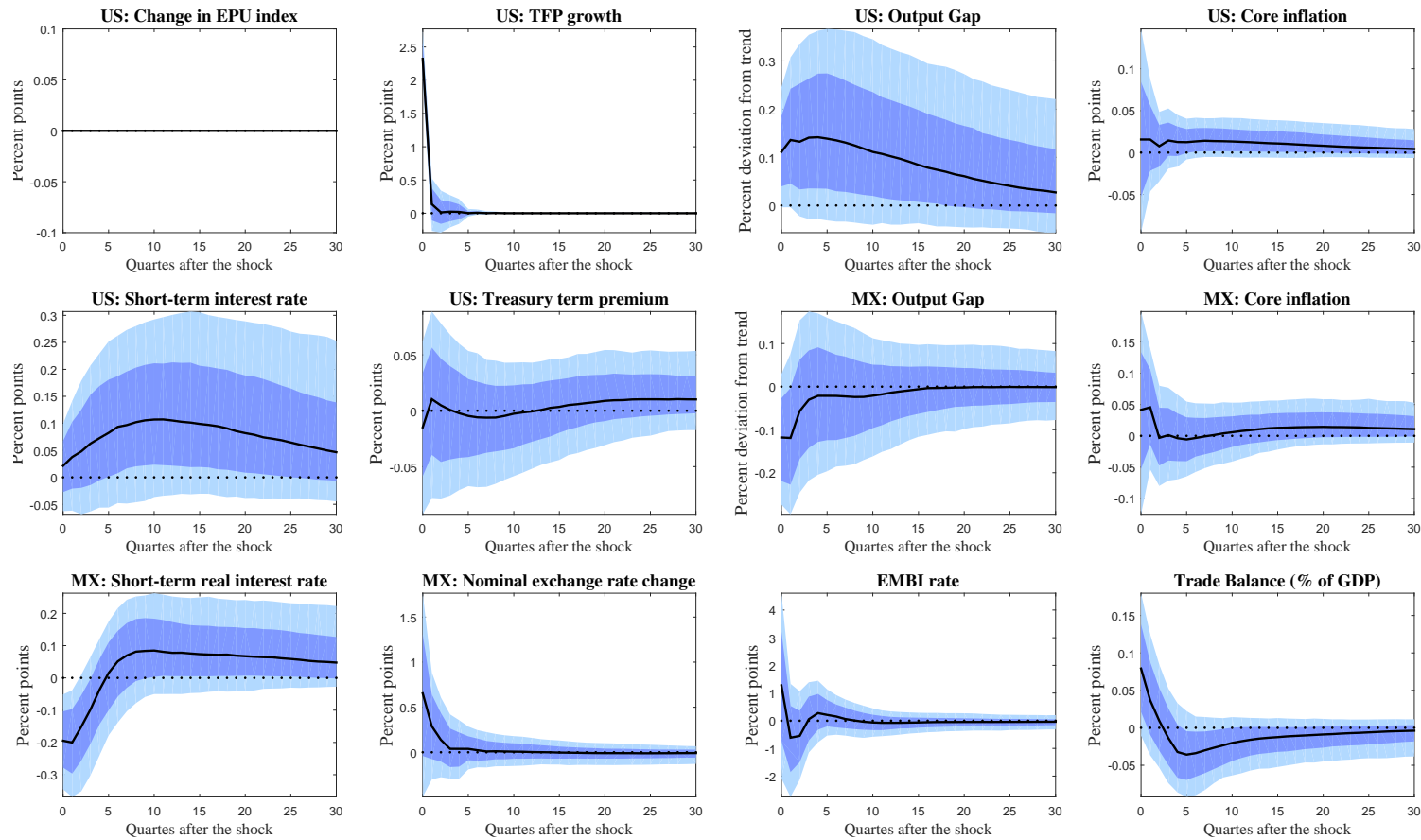

Note: The figure reports the median impulse response as well as the central 68th and 90th percentiles of the distribution of the impulse responses in different shades. 
Figure B.5: Impulse responses to a regular monetary policy shock using a Cholesky identification
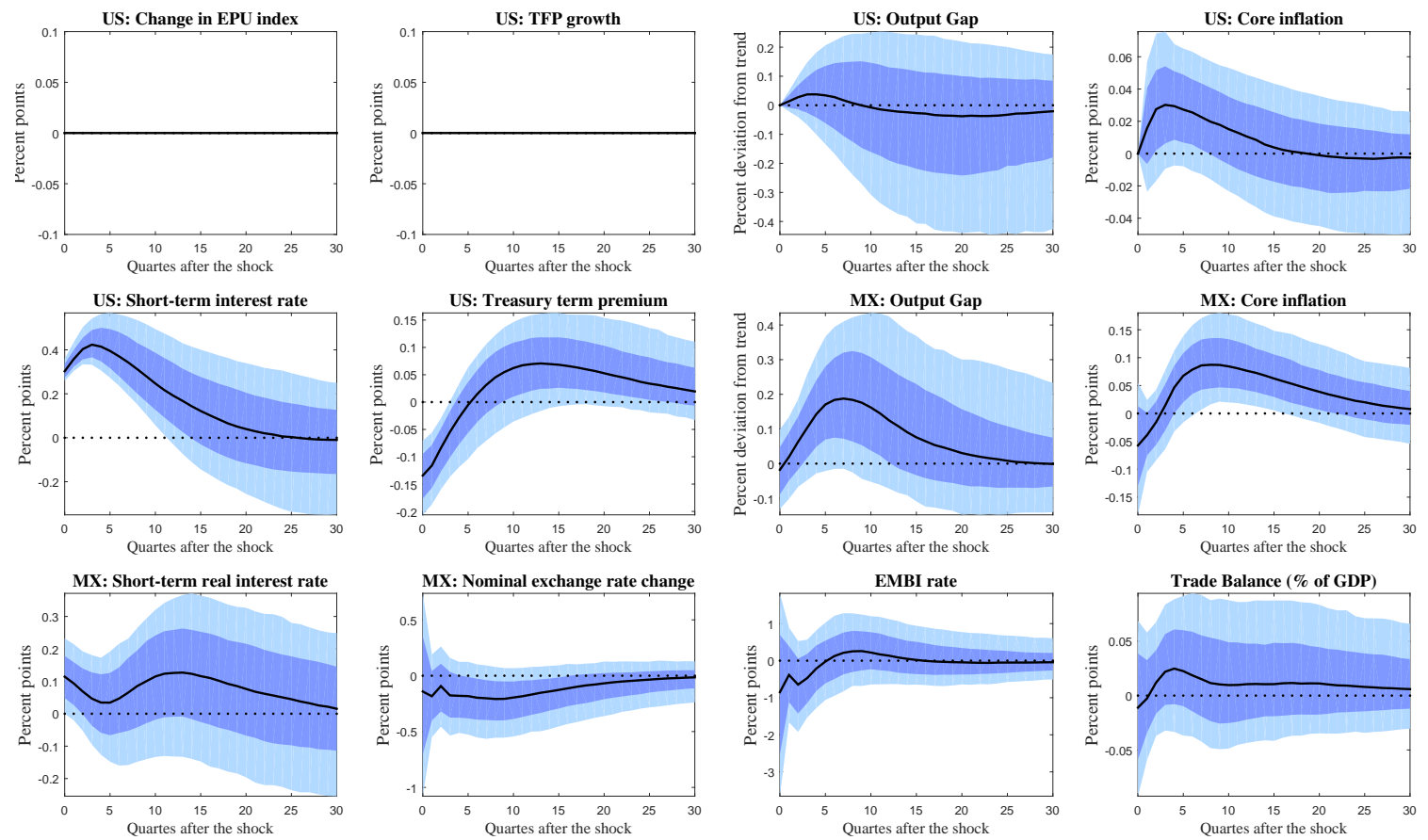

Note: The figure reports the median impulse response as well as the central 68th and 90th percentiles of the distribution of the impulse responses in different shades. 